\title{
PRÁCTICAS Y SABERES DE LA COMUNICACIÓN PARA EL CAMBIO SOCIAL EN LA EXPERIENCIA DE FUNSAREP
}

\section{PRACTICES AND KNOWLEDGE OF COMMUNICATION FOR SOCIAL}

CHANGE IN THE EXPERIENCE OF FUNSAREP

Por: Mercedes Posada Meola ${ }^{1}$

Mary Nieto Ariza ${ }^{2}$

\section{RESUMEN}

Este artículo es resultado del proyecto de investigación "Funsarep: Cuando la comunicación y la cooperación internacional se encuentran en una experiencia para el empoderamiento de las mujeres" y pretende ofrecer un recorrido conceptual y práctico por la experiencia en comunicación para el cambio social de la Asociación del Barrio Santa Rita para la Educación y la Promoción - Funsarep en Cartagena de Indias. Desde un abordaje cualitativo, y sin pasar por alto el eterno debate en torno a la comunicación como ciencia u objeto de estudio, el texto por una parte presenta una lectura crítica de los paradigmas tradicionales, verticalizados y mecanicistas de la información, y por otra aporta evidencias materiales, desde la teoría y la experiencia de Funsarep, sobre cómo una comunicación dialógica, participativa, horizontal y orientada al cambio, es capaz de incidir de manera sostenida en los procesos de formación, autogestión, empoderamiento y transformación que lideran las comunidades organizadas para incidir en su desarrollo.

Para lograr este fin, se realizaron entrevistas en profundidad, se relacionaron testimonios de actores clave con la teoría, se recopilaron y analizaron piezas de comunicación alusivas a las campañas que ha liderado Funsarep en la ciudad durante los últimos diez años y finalmente se hizo un ejercicio de observación participante. El resultado de toda esta experiencia se encuentra en las siguientes páginas.

Palabras clave: Comunicación, cambio social, participación, desarrollo, educación popular.

\section{ABSTRACT}

This article is the result of the research project: "Funsarep: When Communication and International Cooperation find themselves in an Experience for the Empowerment of Women",

\footnotetext{
${ }^{1}$ Magister en Desarrollo social (Uninorte), estudiante de doctorado en Comunicación (U. De La Plata). ORCID: 0000-0003-02026709 mposadameola@gmail.com

${ }^{2}$ Especialista en Comunicación para el Desarrollo Social. Magister en Cooperación Internacional para el Desarrollo. ORCID: 0000-0001-8582-9747 mary.nieto.ariza@gmail.com
} 
and aims to offer a conceptual and practical journey through the communication experience for social change of the Association of the Barrio Santa Rita for Education and Promotion -Funsarep, in Cartagena de Indias. From a qualitative approach and without overlooking the eternal debate around communication as a science or as an object of study, the document presents a critical reading of traditional paradig$\mathrm{ms}$, vertical oriented and mechanistic on information. On the other one, provides material evidence, from theory and Funsarep's experience, on how a dialogical, participative, horizontal and change-oriented communication, is able to have a sustained impact on the processes of formation, self-management, empowerment and transformation led by organized communities to influence their development.

To achieve this end, interviews were conducted and testimonies of key actors were associated to the theory; communication pieces concerning with the campaigns that Funsarep has led in the City during the last ten years were collected and analyzed and finally, an exercise of participant observation was performed. The results of this whole experience are described in in the following pages.

Keywords: Communication, social change, participation, development, popular education.

\section{INTRODUCCIÓN}

Todo artículo tiene su historia. El que aquí se presenta nace de un interés por estudiar y sistematizar la experiencia en comunicación para el cambio social y cooperación internacional de la Asociación Santa Rita para la Educación y la Promoción - Funsarep en Cartagena de Indias cuyo objetivo general es comprender el rol transversal que ha ejercido este tipo de comunicación en los procesos de empoderamiento liderados por esta asociación para generar mayores grados de incidencia y participación en y para sus comunidades. De igual manera, el documento recupera el debate entre dos corrientes fundacionales de las ciencias sociales que han servido para agitar la reflexión en torno a los alcances de la comunicación como ciencia o campo disciplinar, refiriéndose a los teóricos positivistas y a los críticos sociales.

Conscientes de la complejidad de la comunicación y su relación con la sociedad, la política, la economía y en general la vida de la gente, es posible que este debate pueda resultar reduccionista, no obstante se acude a él como punto de partida para dar contexto a un concepto mucho más amplio en donde el papel de la comunicación -como herramienta del desarrollo humano- trasciende el viejo paradigma de la comunicación lineal, vertical y de carácter propagandístico que la caracterizó en sus inicios, para convertirse en un factor aglutinador de la participación y movilización ciudadana, siendo este último donde encuentra la justificación este trabajo. Se refiere a un tipo de comunicación más horizontal, dialógica, democrática y orientada a lograr el cambio social, un concepto que bien puede rastrearse en las estrategias, prácticas y saberes que Funsarep ha acumulado a lo largo de sus 30 años de vida.

El acervo teórico de este artículo en buena parte es tomado de la categoría "Comunicación para el cambio social" abordada en la investigación "Funsarep: Cuando la comunicación y la cooperación internacional se encuentran en una experiencia para el empoderamiento de las mujeres"; no obstante, de manera específica la mencionada investigación se propuso identificar las estrategias, prácticas y saberes de la 
comunicación para el cambio social puestas en marcha por esta Fundación para lograr procesos de formación, empoderamiento y organización en las comunidades beneficiarias de sus distintos programas.

De modo que el trabajo de campo y la revisión documental realizados en torno a esta categoría merecían un espacio propio que pudiera ser consultado tanto por investigadores sociales y estudiantes, como por comunidades o grupos de trabajo que tienen interés en estudiar temas relacionados con el papel de la comunicación en los procesos democráticos, de participación ciudadana, empoderamiento y en general del desarrollo desde la noción de libertad, lo que en definitiva se convierte en otra justificación para este documento.

Para abordar estas temáticas, desde la comunicación para el cambio social recurrimos a autores como Alfonso Gumucio Dagron (2011), Rosa María Alfaro (2006), Alejandro Barranquero (2015), Clemencia Rodríguez (2014), entre otros; si bien la categoría cooperación internacional no fue priorizada en este artículo, conviene decir que para su abordaje fueron consultados los académicos Bruno Allyon (2014), Carlos Tassara (2016) y José Antonio Sanahuja (2016). También se analizaron informes y documentos producidos por diversos organismos internacionales que han trabajado la relación entre comunicación, cooperación y desarrollo como la ONU o el BID. El marco teórico resultante permitió considerar la relación que existe entre estos conceptos, además de establecer una relación teórico-práctica entre lo hallado en los documentos con las acciones ejecutadas por Funsarep, donde se comparten aspectos para mejorar la participación y el empoderamiento de diversos actores del desarrollo que no han sido tomados en cuenta a la hora de la creación de las agendas de trabajo.

Finalmente, la sistematización de esta experiencia sin duda puede dar luces para que se fortalezcan procesos similares en otras localidades o ciudades con características similares a las de este caso, para que nazcan nuevas campañas orientadas a la defensa y garantías de los derechos, para que las comunidades encuentren referentes que les ayuden a potenciar sus mecanismos de organización y autogestión, para favorecer el diálogo y la construcción colectiva de agendas de desarrollo.

\section{Metodología}

El tipo de investigación es cualitativa y aborda una temática social ya que este "permite una recuperación de la subjetividad real de las relaciones sociales, devolviendo el protagonismo y la voz a los propios sujetos" (Posada, 2009, p. 61). De manera que para estudiar de cerca el caso particular de Funsarep, este enfoque, mayoritariamente cualitativo, comprendió un ejercicio de observación participante materializado en el seguimiento a distintas actividades ejecutadas por la Fundación en el marco de su iniciativa "40 días y 40 noches de activismo por el derecho de niños, niñas, jóvenes y mujeres a una vida libre de violencias, segura y en paz en Cartagena y Bolívar" realizada entre las fechas de 1 de noviembre al 10 de diciembre de 2017. La actividad consistió en entender la importancia de vivir en territorios más seguros donde se respeten los derechos humanos, pero también se abran espacios a la participación desde la diversidad. Aquí se observaron diferentes acciones con altos componentes comunicativos como foros, encuentros, 
marchas, plantones, puestas en escenas, vallas publicitarias que contaron con la participación no solo de sus propios colectivos, sino de aliados estratégicos en el desarrollo de su trabajo como la empresa privada y otras organizaciones sociales. "La observación participante es según Taylor y Bogdan (1984) la investigación que involucra la interacción social entre el investigador y los informantes en el milieu (escenario social, ambiento o contexto) de los últimos, y durante la cual se recogen datos de modo sistemático y no intrusito" (citado en: http://www.ujaen.es/investiga/tics_tfg/pdf/cualitativa/recogida_datos/ recogida_observacion.pdf).

La organización del proceso, se hizo de manera bietápica. En la primera etapa se realizó el levantamiento, procesamiento y sistematización de la información encontrada para los antecedentes y el análisis contextual; y en la segunda, se realizó la valoración del proceso de comunicación a través del levantamiento de información con entrevistas a actores claves de la Asociación. El uso de los insumos recogidos tuvo unos rigores para su procesamiento: transferibilidad, integridad, confidencialidad, veracidad, significado de contexto, fidedignidad y validez.

Toda la anterior información logró dos momentos relevantes en la investigación: el primero, el refinamiento del marco teórico con escenarios clave de convergencia entre la cooperación internacional y la comunicación; y el segundo, más pertinente para los fines de este artículo, los resultados de la propuesta que invita a reconocer el trabajo de buenas prácticas comunicacionales de Funsarep frente a temas como empoderamiento, derechos humanos y transformación social.

El artículo también se desprende de un proceso de sistematización que permitió organizar, categorizar, interpretar, comprender y documentar información valiosa de Funsarep como: la relevancia de las problemáticas sociales de las que se ha ocupado y las propuestas para solucionarlas. A su vez se realizó una tarea de recopilación documental a través de informes, publicaciones de la organización, datos estadísticos y material bibliográfico en general, pero también mediante un análisis de contenido de piezas periodísticas y de material publicitario de la organización, tomando en cuenta campañas, piezas y mensajes puestos en circulación. De igual forma, se sintetizaron relatos, testimonios y experiencias de personas que han participado en la construcción de los proyectos liderados por Funsarep, así como de actores representativos de la ciudad de Cartagena que han conocido de cerca el proceso adelantado por esta organización.

En cuanto a las técnicas y/o instrumentos de recolección empleados, los dos más importantes fueron: 12 entrevistas abiertas con una guía de preguntas semiestructuradas, tanto al personal de Funsarep como a actores claves que por su experiencia profesional y académica conocen no solo el contexto de la ciudad, sino el trabajo que esta organización ha realizado durante sus 30 años; y en un segundo momento, la revisión documental a través de informes, publicaciones de la organización, datos estadísticos y material bibliográfico en general. Aquí cabe resaltar la realización de un análisis de piezas periodísticas y de material comunicacional producido por la organización, tomando como referente campañas, piezas y 
mensajes cuyo contenido evidenció su preocupación por las transformaciones sociales que demanda la comunidad cartagenera.

El resultado de todo este recorrido por la teoría y la práctica, se sintetiza mediante tres capítulos: 1. La comunicación como debate: Más que ciencia o campo de estudio, una herramienta para el cambio social; 2. La comunicación para el cambio social en la experiencia de Funsarep y 3. La comunicación también es una herramienta pedagógica para el empoderamiento. Donde en un primer momento, se recupera el debate entre dos corrientes fundacionales de las ciencias sociales que han servido para agitar la reflexión en torno a los alcances de la comunicación como ciencia o campo disciplinar (refiriéndose a los teóricos positivistas y a los críticos sociales). Para luego llevar al lector a la experiencia de buenas prácticas de Funsarep, posteriormente se presenta esa relación teórica-práctica frente al uso de la comunicación para el cambio social como una herramienta para el empoderamiento; para finalmente establecer unas conclusiones y recomendaciones frente a lo investigado.

\section{Resultados}

\section{La comunicación como debate: Más que ciencia o campo de estudio, una herramienta para el cambio social}

¿Ciencia o campo de estudio? Más allá de este debate inacabado en el que siempre confluyen los investigadores de la comunicación, existe un consenso parcialmente aceptado en torno a su definición conceptual primaria: es el proceso social fundamental. Para Miguel de Moragas, un autor catalán que defiende el enfoque crítico (frente al positivista, enfoque en el cual el investigador no constituye un agente de cambio sino un observador objetivo), "la comunicación, más que una ciencia, es un proceso que aparece tanto en los niveles cognoscitivos del individuo como en su acción social” (1981). Beltrán (1985) por su parte, en un artículo publicado a principio de los ochenta, advierte que la investigación latinoamericana sobre la comunicación "ha estado y todavía lo está, considerablemente dominada por modelos conceptuales foráneos, procedentes más que todo de Estados Unidos de Norteamérica". En el mismo sentido Sánchez Ruiz (1992) señala que desde que finalizó la Segunda Guerra Mundial y hasta principio de los años sesenta, Latinoamérica recibió "acríticamente y sin mediaciones ni adaptaciones" los enfoques positivistas prevalecientes en los Estados Unidos: el empirismo, el funcionalismo, el difusionismo y su síntesis: el desarrollismo”.

El paradigma positivista por su parte puede rastrearse en los estudios de Lazarsfeld (1979), Laswswe11 (1986), Katz (1979), entre otros teóricos de la comunicación, y encuentra su expresión material en enfoques y teorías como la aguja hipodérmica, la influencia personal, usos y gratificaciones y el análisis funcional, por citar algunos ejemplos. La mirada positivista fue parcialmente desplazada de las investigaciones comunicacionales latinoamericanas debido a la fuerza que tomó el paradigma crítico social en la tarea de estudiar la comunicación en su contexto más amplio. Este esfuerzo implicó un análisis de los modelos económicos, de las dinámicas sociales y, en consecuencia, un cuestionamiento profundo a las desigualdades económicas, de control y de poder en los sistemas 
políticos y económicos contemporáneos. Los investigadores de esta corriente, son herederos legítimos de la corriente marxista y neomarxista, basados principalmente en los aportes de la Escuela de Frankfurt, Barthes (1987) y Hall (1980), entre otros. De la mediación del enfoque crítico con las aportaciones propias de América Latina surge la escuela culturalista latinoamericana representada entre otros autores por Jesús Martín Barbero (1997) con su libro fundacional "De los medios a las Mediaciones", Nestor García Canclini (1987) y Guillermo Orozco (1990), entre otros.

Este corto recorrido por estas tensiones en torno al estudio de la comunicación es importante porque permite abrir el camino a un concepto de comunicación mucho más próximo para los fines de este artículo: La comunicación para el cambio social, una comunicación que le da protagonismo al receptor como sujeto activo de su proceso comunicativo, y que la plantea desde las necesidades de las comunidades al centrarse no en los comportamientos individuales sino en las normas sociales, las políticas y la cultura de los territorios (Gumucio, 2004) dándole relevancia al proceso comunicativo, al diálogo y al intercambio de saberes.

A la par de estos debates y tras tomar distancia del paradigma funcionalista heredado de la posguerra, poco a poco va naciendo una comunicación donde prevalece más el diálogo basado en argumentos y no en la imposición del poder. De acuerdo con Alfonso Gumucio Dagron (2004), este tipo de comunicación "nace como respuesta a la indiferencia y al olvido, rescatando lo más valioso del pensamiento humanista que enriquece la teoría de la comunicación: la propuesta dialógica".

Y esa relación de diálogo cada vez la va acercando más a un término que va consolidándose: el desarrollo, pero no un desarrollo que veía en las grandes potencias las soluciones a las problemáticas sociales de los llamados países tercer mundistas, sino un desarrollo más humano que propiciara cambios en la calidad de vida de la gente, de las comunidades. Un desarrollo que se acerca más al concepto propuesto por el economista y filósofo Amartya Sen, que va más ligado a la expansión de las libertades del ser humano en donde la pobreza y la falta de oportunidades son los principales obstáculos para su crecimiento y bienestar, con lo cual pasa a un segundo plano el viejo paradigma del crecimiento económico para darle prelación a la educación, el empleo, la vivienda, la salud y todo lo que conduzca a la realización humana.

Cejudo Córdoba defiende que el desarrollo no termina en el aumento de la producción económica nacional, y que por eso su estimación mediante la renta disponible es insuficiente. El desarrollo tiene que ver, más bien, con las cosas que las personas pueden realmente hacer o ser (los llamados funcionamientos), y así con las capacidades de que disponen, entendidas como las oportunidades para elegir y llevar una u otra clase de vida. Es éste el sentido en que una sociedad desarrollada es una sociedad más libre, y en el que el desarrollo es el camino hacia una libertad mayor. (Cejudo, 2007) 
Esta noción del desarrollo, que armoniza bastante bien con la mirada crítica en torno a la linealidad de la comunicación y su papel como herramienta propagandística de los mensajes y modelos dominantes, obliga a ampliar su estudio y sobre todo a trascender la disputa entre positivistas y críticos sociales. El foco ya no son los elementos constitutivos del modelo tradicional de la comunicación (emisor, receptor, referente, canal, mensaje y código) ni tampoco las funciones de los medios (paradigma positivista) sino más bien una versión ampliada del rol de los receptores (vistos no como una masa homogénea y dispersa, como plantearon los frankfurtianos) sino como un sujeto de derecho y un actor clave que en colectivo es capaz de incidir en las decisiones públicas y participar en la transformación de su entorno.

Desde esta perspectiva (heredera de alguna manera del paradigma crítico, en su cuestionamiento a la hegemonía y los vacíos del sistema) se va consolidando un tipo de comunicación que gradualmente se empieza a relacionar más con los programas de desarrollo humano al propender por el derecho a la información y al reconocimiento de la audiencia como sujetos comunicativos activos y no como simples objetos receptores de información (Mercado \& Nieto, 2018). En este contexto, la cooperación internacional, entendida como una herramienta del desarrollo, comienza a ver en la comunicación un instrumento clave para acercarse a las comunidades más que como un vehículo propagandístico o difusor de información. Organizaciones internacionales como la FAO establecen reuniones periódicas con especialistas de la comunicación de otras organizaciones para promover el diálogo especializado e incidir en los niveles de decisión (Gumucio Dagron, 2004). La UNESCO comienza a elaborar informes sobre los desequilibrios de la información en el mundo y el apoyo a experiencias de radio comunitaria, mientras que la UNICEF por su parte, logra potencializar sus grandes movilizaciones sociales (Gumucio, 2004). Es decir, la comunicación se convierte en un puente entre el mundo de la cooperación internacional, la academia, las comunidades y la comunicación propiamente dicha.

Alfonso Gumucio Dagron (2004) en su texto "El cuarto mosquetero: la comunicación para el cambio social", ha dicho que la comunicación es aún considerada por los organismos de cooperación y desarrollo como "la quinta rueda del carro" y que su función es poco entendida por quienes toman decisiones estratégicas. Para este autor boliviano, la comunicación suele ser marginada de los programas de desarrollo o se convierte en un artefacto propagandístico pero en muy pocos casos en un instrumento de diálogo y un elemento facilitador en el proceso de participación ciudadana, una garantía para un desarrollo humano sostenible, propósito que ha persistido tanto en los Objetivos de Desarrollo del Milenio, como en los nuevos Objetivos de Desarrollo Sostenible y a los que tanto los gobiernos, la academia en general y la sociedad civil deben atender. La mirada del profesor Rafael Obregón es un poco menos apocalíptica que la de Gumucio al considerar que la comunicación genera espacios y escenarios para que los cuestionamientos sobre lo que significa el desarrollo se masifiquen, se apropien y se alcancen. Para este autor la comunicación también 
contribuye a la reflexión sobre lo que las comunidades o sociedades creen qué es el desarrollo, facilita entornos para que se determinen las metas y estrategias, permite analizar las realidades de los pueblos y establecer políticas a seguir, y se convierte en una herramienta clave para promover procesos de cambio a nivel político, social, comunitario e individual (Obregón, 2011).

Pero el reclamo de Gumucio Dagron no solo recae sobre las organizaciones de cooperación internacional sino sobre la academia. Para el autor, hasta años muy recientes, la academia mostró absoluto desdén e incluso ignorancia sobre el tema. Pese a ello, las experiencias de comunicación participativa continúan creciendo como respuesta a una situación en las que las voces de la multiculturalidad son negadas o escondidas por los medios masivos.

"La Comunicación para el Cambio Social nace como respuesta a la indiferencia y al olvido, rescatando lo más valioso del pensamiento humanista que enriquece la teoría de la comunicación: la propuesta dialógica, la suma de experiencias participativas y la voluntad de incidir en todos los niveles de la sociedad". (Gumucio, 2004)

Para comprender un poco más la relación entre comunicación y cambio social, es necesario entender cómo se ha visto esta a medida que el concepto de desarrollo ha ido mutando mediante tres paradigmas el primero de ellos el dominante, donde el desarrollo va más relacionado con el crecimiento económico y la producción, toma como punto de referencia los procesos y avances de las grandes potencias para ser aplicados en los menos afortunados. Aquí la comunicación toma un rol más de transmisión masiva en el cual el poder está por encima de la concepción dialógica, dándole relevancia a los grandes medios de comunicación y sus líderes de opinión, estableciendo una relación profunda entre lenguaje y poder (Rodríguez \& Quijano, 2014)

El segundo paradigma se refiere a la dependencia y nace en respuesta al anterior, los países menos ricos cansados de las relaciones de poder impuestas por las grandes potencias y sus procesos homogenizadores, empiezan a entender que en el cambio de esas relaciones de desigualdad está la clave del subdesarrollo y no del desarrollo, es decir, caracterizado por ejercicios más sociales, más justos, más contextualizados y más equitativos. Desde este paradigma, la comunicación analiza más los contextos, se empieza a reconocer el saber local, la tradición y la cultura (Gumucio Dragón, 2004).

Se pasa del énfasis en el mensaje como estructura ideológica a la recepción crítica, en el que se rescata la posibilidad y capacidad de audiencias y públicos de renegociar significados y sentidos, y otro que pasa de la recepción crítica al consumo, el cual surge como un distanciamiento frente a la perspectiva de análisis anteriores y recupera elementos centrados en la noción de sujeto. (Rincón, citado en Obregón, 2011).

El tercer paradigma, el alternativo, nace producto de las diversas transiciones vividas en muchos países. El adiós a las dictaduras y el nacimiento de modelos más democráticos dieron mayor 
cabida a procesos de movilización social y a una mayor pluralidad de voces frente a los modelos de desarrollo dominantes (Obregón, 2011). Cobran relevancia actores sociales que reclamaban mayores índices de participación desde las diversas esferas, es decir, buscaban un cambio social que permitiera mayores índices de equidad, libertad y justicia; el énfasis va es más allá de lo económico, para situarse en lo social, y cultural (Obregón, 2011). En este escenario la comunicación ya se empieza a ver más como un proceso que da voces a quien lo realiza a partir de su empoderamiento, donde la comunidad deja de ser un agente pasivo para convertirse en protagonista de su propia transformación.

Todos estos encuentros entre el desarrollo y la comunicación, han confluido para tejer puentes entre los estados, la sociedad y las comunidades y de alguna manera dar respuesta a los problemas que hacen parte de la agenda global bajo el lente de la cooperación internacional. A continuación, se presenta una síntesis de algunos momentos representativos donde se encuentran el desarrollo, la comunicación y la cooperación internacional:

Tabla 1. Algunos momentos claves de la cooperación y la comunicación para el desarrollo

\begin{tabular}{|c|c|}
\hline $\begin{array}{l}\text { "Voces múltiples, un } \\
\text { solo mundo" o informe } \\
\text { de MacBride. }\end{array}$ & $\begin{array}{l}\text { Propuesta que permitió considerar las problemáticas mundiales comunicacionales, en lo que se refiere a } \\
\text { participación de la prensa y las grandes masas para promover el desarrollo y la paz mundial. } \\
\text { (MacBride,1980) }\end{array}$ \\
\hline $\begin{array}{l}\text { Haciendo olas: } \\
\text { Comunicación participativa } \\
\text { para el cambio social }\end{array}$ & $\begin{array}{l}\text { Publicación que contiene } 50 \text { relatos comunitarios creados y contados desde las propias historias de sus } \\
\text { protagonistas y quienes comienzan a cambiar las circunstancias de su pobreza, discriminación y exclusión } \\
\text { a partir de experiencias comunicativas. (Gray-Felder 2001, Citado por Mercado \& Nieto, 2018:61) }\end{array}$ \\
\hline $\begin{array}{l}\text { Acuerdo de } \\
\text { sobre la eficac }\end{array}$ & $\begin{array}{l}\text { Ambas iniciativas cuentan con elementos como apropiación democrática, la rendición de cuentas y la } \\
\text { gestión basada en resultados de desarrollo que difícilmente se pueden alcanzar sin la comunicación como } \\
\text { componente central (Del Río, 2012) }\end{array}$ \\
\hline s del Milenio & $\begin{array}{l}\text { Aunque no se refiere a la comunicación de manera explícita, algunos autores consideran que ellos en sí } \\
\text { mismo si lo son. } \\
\text { "The MDGs as a Communication Tool for Development, considera que, una vez adaptados al contexto } \\
\text { nacional y local, el marco de los ODM tiene el potencial de funcionar como una herramienta de comunica- } \\
\text { ción para el desarrollo. Al mismo tiempo, mejorar el diálogo público sobre los Objetivos de Desarrollo del } \\
\text { Milenio puede contribuir a su consecución" (Del Río, 2012) }\end{array}$ \\
\hline ss de Desarrollo & $\begin{array}{l}\text { Existen de manera explícitas tres metas que se refieren al uso de la comunicación: } \\
\text { - Mejorar el uso de la tecnología instrumental, en particular la tecnología de la información y las comu- } \\
\text { nicaciones, para promover el empoderamiento de la mujer. } \\
\text { - Garantizar el acceso público a la información y proteger las libertades fundamentales, de conformidad } \\
\text { con las leyes nacionales y los acuerdos internacionales. } \\
\text { - Garantizar la adopción en todos los niveles de decisiones inclusivas, participativas y representativas que } \\
\text { respondan a las necesidades. } \\
\text { (www.un.org/sustainabledevelopment/es/objetivos-de-desarrollo-sostenible/) }\end{array}$ \\
\hline
\end{tabular}

Fuente: Elaboración propia

\section{La comunicación para el cambio social en la experiencia de Funsarep}

Un punto de encuentro de los elementos mencionados anteriormente (comunicación, desarrollo y cooperación internacional) y al que hace referencia este artículo es la Asociación Santa Rita para la Educación y la Promoción - Funsarep en la ciudad de Cartagena, una organización que por 
más de 30 años ha trabajado por la promoción, defensa y exigibilidad de los derechos humanos de su comunidad (niños, niñas, adolescentes y mujeres) para el fortalecimiento de su actuación como ciudadanos y ciudadanas en la gestión de su desarrollo local (http://funsarep.org/dimensiones-de-actuacion/) favoreciendo el dialogo, posicionando agendas y dándole protagonismos a las comunidades donde la comunicación ha sido su eje transversal y la cooperación su principal aliado desde lo económico pero también desde apuestas en común:

Sin comunicación no hay ejercicio de ciudadanía. En Funsarep hemos entendido la comunicación como ese dador de voces que propicia ejercicios democráticos a partir del diálogo. Y a su vez entendiéndola desde todos sus roles, para el desarrollo, para la creación de contenidos y para el relacionamiento interno y externo de la organización. (Carlos Díaz, comunicador social de la organización adscrito al área de derechos de niños, niñas y columnista de opinión, comunicación personal, 20 de septiembre de 2017).

Todo este ejercicio le ha permitido a Funsarep consolidarse como una organización con amplio reconocimiento social y articularse con otras apuestas convirtiéndolos en aliados estratégicos. En este sentido tiene alianzas internacionales, nacionales, locales, comunitarias, entre otras (S. Bermúdez, comunicación personal, 1 de febrero de 2018). Pero no solo las alianzas son un logro representativo en el trabajo de Funsarep, también son las redes, los colectivos o los grupos que se han venido gestando a partir de las necesidades que sus comunidades demandan, porque entienden que por más que se trabaje de manera unificada, hay características que hacen a los seres humanos diversos desde sus particularidades. Tal es el caso de procesos que buscan empoderar a las mujeres, a las víctimas del conflicto armado, a los niños y niñas, comerciantes e inclusive a los hombres.

Hemos tenido la oportunidad de crear colectivos con hombres. En una ocasión lo hicimos con hombres jóvenes, y desde el principio entendimos que, si queríamos que ellos se apropiaran de esta iniciativa, era necesario que el punto de encuentro no fuera un salón convencional, sino por el contrario buscar esos espacios donde normalmente nos encontraríamos los hombres: la esquina, la cancha, ya eso enseguida tiene un impacto en términos de apropiación del territorio, del espacio. de la ciudad. (C. Diaz, comunicación personal, 1 de febrero de 2018).

Cerca del sector de Funsarep, se encuentra el mercado popular para comerciantes, un espacio al que en sus inicios los gobiernos locales no le prestaron atención y se fue deteriorando pero que gracias al ejercicio de sus propios comerciantes con el apoyo de Funsarep y otras organizaciones finalmente fue remodelado. Sin embargo, hoy dos años después, aún no funciona. Ahora la lucha se ha centrado en el miedo que los comerciantes tienen frente a algún tipo de adjudicación que se le pueda hacer a una multinacional y no a que sean los comerciantes locales quienes trabajen en él. Situación que los ha llevado crear su propia organización de comerciantes, estableciendo veedurías ciudadanas, con la característica particular que la mayoría de sus miembros son mujeres. (I. Díaz, comunicación personal, 1 de febrero de 2018). 
Pero, así como se han creado estas organizaciones y veedurías de comerciantes, Funsarep ha sido la célula de varios grupos, colectivos y organizaciones que han hecho de la comunicación el hilo conductor de su gestión, iniciativas que hacen parte de un tejido organizativo y social, para una lucha mucho más grande, sostenida y fuerte, es decir, se parte de un proceso individual para llegar a un colectivo que les permite unirse y organizarse.

Tabla 2. Colectivos / Grupos y sus apuestas desde lo comunicativo

\begin{tabular}{|l|l|}
\hline Asociación artística de mujeres espejo & $\begin{array}{l}\text { Una asociación que interactúa en lo público, privado e íntimo, con una apuesta política } \\
\text { y ciudadana, participando como sujetas de derechos e incorporando la formación y la } \\
\text { capacitación a través de la lúdica, el arte, el teatro de género, los rituales, los elementos } \\
\text { de la naturaleza y los procesos psicoterapéuticos. }\end{array}$ \\
\hline Colectivo Violeta & $\begin{array}{l}\text { Colectivo de adolescentes víctimas y no víctimas de violencia que a través de la puesta } \\
\text { en escena realizan obras de teatro testimoniales contando un poco sus vivencias frente a } \\
\text { las violencias que viven sus comunidades. }\end{array}$ \\
\hline Equipo Mujeres con voz propia & $\begin{array}{l}\text { Grupo de mujeres que reconocen a partir del ejercicio comunicacional su autoridad de } \\
\text { y la de sus antecesoras, el saber que hay una historia donde las mujeres también son } \\
\text { importantes y que son capaces de incidir en temas tan claves como la construcción de } \\
\text { iniciativas, la participación política, el respeto por sus derechos entre otras. (Mercado \& } \\
\text { Nieto, 2018) }\end{array}$ \\
\hline Niñas con voz propia & $\begin{array}{l}\text { Un espacio para que las niñas y jóvenes también reconozcan su propia historia y desde } \\
\text { allí se empiece la exigencia de sus derechos y demandas, es decir que sus voces sean } \\
\text { escuchadas para hacerle freten a sus necesidades particulares. }\end{array}$ \\
\hline Una ciudad, un metro diez & $\begin{array}{l}\text { Una iniciativa comunicativa y lúdica para construir ciudad a partir del autoreconocimien- } \\
\text { to de los niños y niñas como ciudadanos y ciudadanas desde un ejercicio de escucha, } \\
\text { de respeto de sus derechos, de atención a sus demandas, pero bajo sus propias miradas. }\end{array}$ \\
\hline Mujeres contra la memoria y el olvido & $\begin{array}{l}\text { Grupo de mujeres víctimas del conflicto armado quienes a través de la formación y el } \\
\text { teatro han podido sanarse y fortalecer su confianza para empoderarse y ser voceras frente } \\
\text { a temáticas como el derecho al a verdad, a la justicia, a la reparación, entre otras. }\end{array}$ \\
\hline
\end{tabular}

Fuente: Elaboración propia

Funsarep se ha caracterizado por tener una comunicación horizontal y dialógica tanto en sus integrantes como en las comunidades con las que trabaja, caracterizada por la participación, la inclusión, la escucha activa, la otredad y el respeto por las diferencias.

"Se trata de una comunicación más horizontal y participativa que también reconoce al otro y a la otra como una persona que sabe, que conoce, que tiene experiencias, que tiene conocimientos y aparece ahí otra categoría comunicativa: la de los saberes. Si tú sabes y yo sé en ultimas no se trata de una transmisión de conocimiento y de saberes sino de poner en diálogo ese saber y realizar ejercicios de construcciones colectivas". (C. Díaz, comunicación personal, 1 de febrero de 2018).

Un momento clave que de alguna forma permitió organizar las comunicaciones en Funsarep, fue la creación de un Departamento de Comunicación para el Desarrollo. Al ser la comunicación un eje transversal en cada una de las apuestas de la organización para sus integrantes, era necesario darle 
un orden y asumirla desde sus diferentes posibilidades.

A medida que los años pasaban vimos la necesidad de organizarnos a través de un Departamento de Comunicaciones para el Desarrollo, entender que todas las dimensiones de la comunicación son importantes, pero sin olvidar su principal característica, a escala humana, donde los sujetos son lo más importante, el reconocer esa historia y de ver el presente y el futuro para la toma decisiones. (C. Díaz, comunicación personal, 1 de febrero de 2018).

El situar al sujeto por encima de los medios y de cualquier sistema social o político (Gil, 2017) les permite apropiarse y ejercer su propia comunicación generando transformaciones. Cuando una persona realiza cualquier actividad a partir de su experiencia no solo le es más fácil transmitirla, sino que al receptor también le es más sencillo identificarse y generar respuestas que enriquezcan el proceso. De manera que a la comunicación hay que entenderla más allá de un simple mecanismo para transmitir información y pensarla en un sentido más experiencial -poner en común, compartir e intercambiar experiencias- (Nieto, 2015).

"En una oportunidad no teníamos textos escolares y entonces elaboramos unas fichas con dibujos producidas por los mismos estudiantes. Otra experiencia fue un material clásico que elaborábamos llamado Camarón que se duerme, se lo lleva la corriente. Este ejercicio se convirtió en nuestra cartilla para los procesos de educación de esa época. Habla mucho de lo que pretendíamos: llamar a la toma de conciencia, a la participación, a no dejar nuestro destino en manos de otra gente. Otra experiencia, fue el abordaje de la foto, de la herramienta del revelado. Para ello hemos realizado talleres de fotografía, de revelado y su armado. También hemos hecho ejercicios para la construcción de guiones y en líneas generales manejo de técnicas y elementos que nos permitan poner en práctica diversas herramientas de la comunicación para incidir en el cambio. (C. Diaz, comunicación personal, 1 de febrero de 2018).

Durante una sesión fotográfica con niños y niñas, ellos empezaron a contarnos cómo se sentirían si no tuvieran miedo, si pudieran ser libres y eso se expresó en un plegable que contenía no solo las fotos sino los textos de los chicos y chicas. El ver plasmadas sus propias historias crea uno lazos más significativos al mismo tiempo que los empodera frente a una causa en particular. (Soledad Bermúdez. Comunicadora social adscrita al área de Derechos de las Mujeres de la organización, comunicación personal, 1 de febrero de 2018)

Parte del Colectivo Violeta hizo unas encuestas para saber qué tipo de violencias se vivían en las comunidades de Bonanza y El Palón y todo ese registro fue llevado a la Secretaría de Educación, a la Alcaldía, a las emisoras. Es que esas situaciones encontradas no son normales, no son justas y no se las merece nadie, por lo tanto, tenemos que denunciar, reclamar, para que se garanticen nuestros derechos y se den las transformaciones necesarias. (Zandra Morales. Psicóloga del Centro de Asesoría Sicosocial y Legal, comunicación personal, 1 de febrero de 2018)

Pero Funsarep no restringe su labor a las comunidades de su área de influencia, sino que se 
proyecta a la ciudadanía en general con campañas cívicas que buscan tener presencia en la ciudad y lo hace con propuestas comunicativas, porque entiende que, si se busca el desarrollo humano, en su sentido más relacional con la libertad, la comunicación es un vehículo poderoso.

"La primera vez que tuvimos la osadía de hacer una obra de teatro en el sector del Reloj Público, todo el mundo me decía: ¿tú te vas a desvestir allí? Yo iba a usar una malla color piel que parecía que estuviera desnuda, para mi sorpresa no hubo nadie que se espantara o nos criticara, por el contrario, la gente estuvo atenta y participativa y ahí nos dimos cuenta que la ciudad quiere ver este tipo de apuestas, obras de teatro públicas, que sensibilicen y que ayuden a la denuncia de la situación de violencia”. (Z. Morales, comunicación personal, 1 de febrero de 2018)

Todo lo que tiene que ver con puesta en escena, murales, recorridos para el reconocimiento de la ciudad de Cartagena como territorio, obedece a un propósito más amplio: cómo las mujeres nos apropiamos del Centro Histórico en la noche sin sentir miedo a ser violentadas o excluidas. Somos mujeres populares afrocolombianas, que pocas veces tenemos acceso al centro porque suele ser un privilegio para los turistas. Entonces la apuesta, es precisamente esta: que a pesar de los obstáculos que tenemos en nuestros barrios populares para acceder al centro en la noche, la comunicación permita que todas veamos la ciudad con su Centro Histórico incluido y nos reconozcamos con nuestro derecho a esta ciudad, a habitarla, a vivirla, a sentirnos parte de ella. (Nelsy Ariza, Coordinadora del área Mujeres y Derecho, comunicación personal, 23 de noviembre de 2017

Todas estas apuestas desde la comunicación permiten que los actores locales se sientan parte de su transformación, pero también que vinculen a otros frente a sus demandas.

\section{La comunicación también es una herramienta pedagógica para el empoderamiento.}

El camino andado hasta aquí inevitablemente conduce a mirar la relación entre la comunicación y la educación. Ambas están inmersas en la interacción entre los sujetos, ya que una comunicación adecuada no podrá lograrse de no mediar un proceso educativo que permita el desarrollo de la capacidad de comunicarse (Barrientos \& Ryan, 2017) y viceversa. Pero este proceso educativo, más allá de las instituciones educativas formales o los medios tradicionales de comunicación, ocurre desde las mismas organizaciones sociales que pueden tomar distancia de las concepciones hegemónicas (muchas veces reforzadas en los enfoques tradicionales de los textos escolares), fueron diseñando sus propias formas para educar. Es decir, se piensa esta relación en un sentido horizontal y dialógico que estimula más la expresión que la transmisión de los educadores (Kaplún, 2007).

A medida que fue perdiendo fuerza la idea de los medios como escuela, se abrió más el debate sobre qué entender por educativo en los medios y en la comunicación en general. Aquí la perspectiva dialógica encuentra su paralelo en el plano educativo: el diálogo de saberes y no la mera transmisión, propuesta central del pensamiento de Paulo Freire (1969). Por otro lado, 
se empieza a evitar el didactismo de los programas educativos para aprovechar más bien los recursos narrativos típicos de los medios. (Kaplún, 2007)

Este protagonismo de lo educativo desde lo social, poco a poco fue acercando más la comunicación a lo popular, a lo de las bases, a lo grupal y a ese encuentro de saberes mencionado anteriormente, a una educación mucho más par, una educación popular entendida como "la dimensión educativa de la acción socio-política" de los movimientos populares (Núñez,1985, citado en Kaplún, 2007), y a una comunicación que se refiere más al posicionamiento de los intereses de estos sectores, entendiendo que hay otros modos (distintos a los hegemónicos) de construir sociedad, ciudadanía y cultura democrática. (Kaplún, 2007)

A partir de esta concepción, Funsarep considera que su primer ejercicio comunicativo lo realiza desde la esfera de la educación popular, debido a que para ellos es imposible ser ciudadanos y ciudadanas sin tener voz, palabra, e inclusive una imagen propia de lo que se quiere (C. Díaz, comunicación personal, 20 septiembre 2017). Es decir, la formación y la capacitación va más allá de talleres y cursos y consiste en analizar y generar estrategias de intervención con la comunidad utilizando su potencial educativo y comunicativo. Lo que de alguna manera conlleva al fortalecimiento de una de sus apuestas: la apropiación de los seres humanos como agentes activos de su propio desarrollo a partir de sus experiencias colectivas e individuales al "formar en ellos un sentido de orgullo, dignidad y confianza en sí mismos para que alcancen un nivel político y social de autonomía" (Puiggros et al, 2017).

La mediación comunicativa siempre ha estado presente en el gran discurso metodológico y educativo que hemos tenido y este se ha dado desde la educación popular, un proceso que empezó en los años 80 y que se ha ido nutriendo, porque aún sin estar profesionalizados todos hemos sido comunicadores pedagógicamente hablando, al no sentirnos identificados con los procesos de educación formal, debido a que creemos que la educación está en los barrios y que allí los procesos comunicativos deberían tender puentes entre sujetos y sujetas, entre barrios y comunidades, entre sectores y temáticas y que a partir de allí ellos construyan sus propios relatos. (Edilberto Noguera Meléndez, Director Ejecutivo y Administrativo, comunicación personal, 23 de noviembre de 2017).

Desde un principio se han asumido los procesos educativos como comunicativos y de concientización bajo una dimensión política, porque la educación popular es una educación política, es una educación transformadora de las realidades desde donde empiezan a aparecer una serie de puntos, de principios, de metodologías a partir de la realidad para llegar a esa misma realidad que se pretende transformar. (C. Díaz, comunicación personal, 1 de febrero de 2018).

La comunicación es una dimensión importante porque no solamente es ver, dar y actuar porque como decimos el que no cuenta no cuenta y resulta que todas las experiencias son importantes y nosotros como institución que trabajamos bajo la educación popular sabemos que los saberes 
se construyen colectivamente y hay que comunicar esos saberes que se van produciendo en la interacción cotidiana, que estamos haciendo y como vamos avanzando. (N. Ariza, comunicación personal, 23 de noviembre de 2018)

A medida que las personas se apropian de sus mensajes y medios comunicativos, va surgiendo entonces su capacidad para empoderarse y desde ahí empezar a hacer ejercicios que divulguen, movilicen y sensibilicen sus causas. Esta comunicación para el empoderamiento desde la educación popular ha sido en definitiva la clave para el trabajo en Funsarep, porque lo que se busca no es que Funsarep comunique, sino que lo hagan los mismos sujetos. De acuerdo con Edilberto Noguera, "Cartagena tiene muchos relatos y testimonios en torno a la historia, en torno a la cultura, lo popular, a lo blanco, lo céntrico, lo periférico, entonces nosotros creemos que es importante desarrollar esos procesos, pero construyendo los contenidos con los propios sujetos" (comunicación personal, 23 de noviembre de 2017).

La experiencia de Funsarep habla de un empoderamiento que se va construyendo o descubriendo desde el reconocimiento de los derechos y sus demandas, entendiéndolo como la capacidad que tienen los seres humanos para autoreconocer su poder frente a una temática y a partir de allí empezar a generar transformaciones en sus vidas (Rubio \& Escofet, 2013).

Ligado al tema del empoderamiento, es importante que la gente crezca o amplíe las capacidades que ya tiene, no es que carezca pero que tenga mayores capacidades, conocimientos y saberes, pero también mayores habilidades en sus ejercicios de liderazgos. (C. Díaz, comunicación personal, 1 de febrero de 2018)

Para Funsarep es importante el sujeto humano, que la mujer tenga voz propia, que nosotras no tengamos que siempre estar hablando por ellas, sino que ellas asuman su propia voz, ese es el verdadero empoderamiento. (Z. Morales, comunicación personal, 1 de febrero de 2018)

En términos de resultados nosotros preferimos hablar de transformaciones, trabajamos por el logro de transformaciones personales y colectivas y desde la perspectiva de las identidades de las personas. Qué ocurre con las personas como mujer, joven, niño, niña, hombre. Entonces se puede decir que en este tiempo ha habido y sigue habiendo un grupo de personas que se han transformado desde la percepción de sí misma, desde su participación. (I. Diaz, comunicación personal, 1 de febrero de 2018)

Esta comunicación, ligada al empoderamiento, permite entender la lógica comunicativa en la incidencia no solo en los medios sino en la capacidad de influir en el otro como parte de una actuación más política, donde se ve a la comunicación más allá de un medio de transmisión de información y se entiende como una herramienta que posibilita transformaciones sociales a partir del uso adecuado de mensajes y canales, la selección de alianzas y redes, la escogencia de actores y acciones 
entre otro aspectos que sin duda alguna permitirán una mayor presencia y apropiación de dicha propuesta en el colectivo, posibilitando una participación mayor participación en las agendas públicas locales.

"Nosotros creemos que es importante que en Cartagena se desarrollen más procesos comunicativos alternativos, de comunicación con niños y niñas, de comunicación con hombres y mujeres populares, de comunicación para la paz. Porque creemos que esa mediación aporta nuevos elementos para la interlocución, para el relacionamiento de los sujetos con los diversos actores sociales y ofrece posibilidades de que esos mismos sujetos puedan enunciar su voz en una ciudad como Cartagena. (E. Noguera, comunicación personal, 23 de noviembre de 2018)

Hoy, el trabajo de Funsarep es conocido y admirado, un trabajo que por más de 30 años ha contribuido a una ciudad más incluyente con sus ciudadanos y ciudadanas, a una ciudad que mire más a sus periferias, con habitantes que se sienten más partícipes en sus territorios pero que siguen luchando frente a las inequidades sociales de las que son víctimas. Grupo poblacionales como el de las mujeres, que por muchos años han sido segregadas por la historia al no ser reconocidas como seres políticos; o como los niños y niñas y jóvenes cuyas opiniones no son tomadas en cuenta por considerarlos los actores más débiles de la sociedad; o el de los mismos hombres quienes han ido entendiendo que los derechos son para todos sin importar los roles establecidos... Todos ellos han encontrado en esta organización un espacio que les ha permitido entender que son sujetos de derechos y que el Estado cómo garante de ellos debe velar por su cumplimiento.

La experiencia de Funsarep es maravillosa no solamente en el tema de género y mujeres sino en el tema de nuevas masculinidades. Allí ha hecho un trabajo hermosísimo. Funsarep ha logrado una credibilidad importante en la ciudad, yo creo en ellos en el trabajo que hacen, he visto los resultados del trabajo y creería que es una organización digna de imitar. (Olga Acosta, antigua consultora agencia de cooperación GTZ, comunicación personal, 6 de febrero de 2018)

...organizaciones como Funsarep conocen y promueven los procesos de exigibilidad de derechos locales en plataforma regionales y transnacionales en respuesta a los mitos de la realidad social en una ciudad como Cartagena con la creación de escenarios, centros de estudio y análisis urbanos del territorio y sus habitantes. (Burgos, 2016, citado en Nieto \& Mercado, 2018:13)

...una de las razones de ser de Funsarep es el empoderamiento de las mujeres a partir de su reconocimiento como ser político. Podríamos decir que Funsarep ha sido una institución que ha alimentado los procesos de empoderamiento de las mujeres al permitirles darse cuenta de que tiene unos derechos y exigirlos y aprender las leyes. Ha sido un trabajo realmente maravillo no solo para las mujeres sino para las comunidades populares y de base de la ciudad de Cartagena. (Dunia León Fajardo, coordinadora de la RPM regional Bolívar - Ruta Pacífica de Mujeres, comunicación personal, 23 de noviembre de 2017) 


\section{CONCLUSIONES Y RECOMENDACIONES}

¿Ha logrado la comunicación convertirse en una herramienta para lograr el cambio mediante acciones a favor del empoderamiento? Esta pregunta sin respuesta absoluta es el punto de partida para presentar nuestras conclusiones y recomendaciones sobre la experiencia de Funsarep, una organización que a lo largo de 30 años ha puesto en práctica estrategias de comunicación para el cambio social -con un financiamiento proveniente de cooperación internacional- para empoderar a las comunidades:

- Funsarep ha ejercido una comunicación horizontal y dialógica, en su propósito de dar voz a colectivos y comunidades que por mucho tiempo han sido invisibilizados tanto en las agendas mediáticas, como en las del desarrollo. Ha encontrado en este tipo de comunicación un vehículo para generar escenarios, identificar aliados, construir iniciativas y fomentar la participación y la incidencia en los procesos de desarrollo con los sujetos y sujetas como sus principales protagonistas.

- La organización ha entendido que la comunicación es cambiante, que ha pasado de ser un mecanismo de transmisión a ser una herramienta de apropiación para las comunidades en el objetivo de dar a conocer sus miradas, fortalecer sus mecanismos de organización y participación en las decisiones públicas. Desde esta perspectiva, Funsarep asume la comunicación como un proceso amplio del que se despliegan unas dimensiones con igual relevancia y vitales para el logro de resultados, con dimensiones para el relacionamiento interno y externo, para la creación y posicionamiento de medios propios, para la construcción de contenidos y mensajes y para el reconocimiento del ser humano como sujeto de derecho y actor de su propio desarrollo.

- La educación popular, en comunión con la comunicación, ha sido una estrategia formativa que va más allá de la educación formal y permite rescatar las experiencias y vivencias que se dan desde los mismos contextos comunitarios para tejer puentes entre sus habitantes, construir relatos y contenidos propios para estimular el pensamiento crítico y transformador de la realidad. Desde esta mirada, la comunicación para el cambio social prioriza y dignifica el saber comunitario, promueve el intercambio de conocimientos y el aprendizaje por medio del diálogo y la participación.

- La organización reconoce la importancia del uso de la tecnología para responder a las necesidades y requerimientos comunicacionales, pero lo hace bajo un ejercicio formativo ordenado y no arbitrario. En este sentido, se han realizado procesos de formación en el manejo de cámaras de video y fotográficas, en producción de textos y otras piezas de comunicaciones, uso de computadores y redes sociales, entre otros. De esta manera han generado una capacidad instalada y de apropiación por parte de los actores involucrados, al ser ellos capaces de definir, según la naturaleza del proyecto o campaña, cuáles son los recursos o medios más apropiados. 
A partir de lo anterior, se reafirma que la comunicación para el cambio social es un proceso dinámico, que no es posible abordar solo con definiciones académicas. Una vez una comunidad o persona entiende el poder de una comunicación dialógica, participativa y democrática, en donde la construcción y puesta en circulación de los contenidos comunicacionales se hacen en colectivo, sus procesos adquieren un sentido de apropiación mucho más sólido, con lo cual se dinamiza la gestión, se fortalecen los lazos y en consecuencia se establecen redes con otras organizaciones para posibilitar cambios más profundos y consolidar procesos sostenibles en el tiempo. En este mismo sentido, esta característica más social de la comunicación ha logrado calar en contextos tan complejos como el desarrollo o la cooperación internacional, los cuales han encontrado en ella un aliado para el crecimiento de las comunidades, comunidades que reconocen que sus voces y accionar son parte activa de su transformación y que a partir de sus organizaciones sociales (como representantes de la sociedad civil) pueden entablar alianzas con y desde el mundo de la cooperación internacional.

\section{REFERENCIAS BOBLIOGRÁFICAS}

Alfaro, R.. (2006). Otra brújula. Innovaciones en comunicación y desarrollo. Lima: Calandria.

Ayllón, B. (2014). La gobernanza de la cooperación y el rol de las organizaciones de la sociedad civil en la Cooperación Sur-Sur. Revista Internacional de Cooperación y Desarrollo, 1(2), 57-89.

Barbero, J. M. (1987). De los medios a las mediaciones: Comunicación, cultura y hegemonía, Gustavo Gili, México.

Barranquero, A. (2015). Trayectorias, cruces y diálogos entre la tradición latinoamericana y anglosajona en comunicación comunitaria y ciudadana. Revista Internacional de Comunicación y Desarrollo (RICD), 1(1), 19-22.

Barrientos, M. A., \& Ryan, S. L. (2017). Relación entre extensión, educación y comunicación.

Barthes, R. El susurrodel lenguaje, Barcelona, Paidos, 1987.

Beltrán, Luis Ramiro (1985). "Premisas, objetos y métodos foráneos en la investigación sobre comunicación”. En Escuelas y Autores, Gustavo Gili, Mass Media, Barcelona.

Del Río, O. (2012). Comunicación sobre/para resultados de desarrollo de iniciativas de cooperación pública. Barcelona: Oficina de Coordinación y Orientación del Programa URB-AL III. Guías Metodológicas, 3.

Funsarep. (2019). Qué hacemos/dimensiones de actuación. Recuperado de: (http://funsarep.org/ dimensiones-de-actuacion/) 
García Canclini, N. (1987). Políticas culturales y crisis de desarrollo: Un balance latinoamericano. Grijalbo.

Gil, J. I. C. (2017). Nuevas formas de entender la comunicación para el desarrollo. Revista de la Asociación Española de Investigación de la Comunicación, 4(8), 27-36.

Gumucio-Dagron, A. (2011). Comunicación para el cambio social: Clave del desarrollo participativo. Signo y pensamiento, 30(58), 26-39.

Gumucio Dagron, A. (2004). El cuarto mosquetero: La comunicación para el cambio social. Investigación \& Desarrollo, 12(1).

Cejudo Córdoba, R. (2007). Capacidades y libertad: Una aproximación a la teoría de Amartya Sen.

Hall, Stuart (1980) “Encoiding/Decoding, en Struart Hall, Dorothy Hobson, Andrew Lowe y Paul Willis (eds.), Culture, media, language, Hutchinson, Londres.

Jakobson, R., \& Mirsky, P. D. (1977). El caso Maiakovski. Icaria.

Kaplún, G. (2007). La comunicación comunitaria. AAVV: Medios de comunicación. El escenario iberoamericano. España, Fundación Telefónica y Ariel, 311-320.

Katz y Paul Lazarsfeld (1979), La influencia personal: El individuo en el proceso de comunicación de masas. Editorial Hispano Europea, Barcelona.

La observación/La Observación participante. Recuperado de: http://www.ujaen.es/investiga/tics_ $\mathrm{tfg} / \mathrm{pdf} /$ cualitativa/recogida_datos/recogida_observacion.pdf

Lasswell, Harold (1986), "Estructura y función de la comunicación en la sociedad”, en M. de Moragas (ed.), Sociología de la Comunicación de Masas:II. Estructura, funciones y efectos, Gustavo Gili, Barcelona.

MacBride, Sean. (1980). Voces Múltiples.

Mercado J. \& Nieto M. (2018) Funsarep: Cuando la comunicación y la cooperación internacional se encuentran en una experiencia para el empoderamiento de las mujeres. (Tesis Maestría Universidad San Buenaventura, Cartagena)

Moragas, Miquel de (1981), Teorías de la comunicación, Gustavo Gili, Barcelona.

Nieto Ariza, M. (2015). La comunicación, herramienta de construcción de liderazgos en organizaciones 
Mercedes Posada Meola - Mary Nieto Ariza

sociales de mujeres afrodescendientes del Caribe colombiano. Encuentros, 13(1).

Organización de las Naciones Unidas. (2019). Objetivos de desarrollo sostenible. Recuperado de www.un.org/sustainabledevelopment/es/objetivos-de-desarrollo-sostenible/

Obregón, R. (2011). Comunicación, desarrollo y cambio social. Portal Comunicación. Com. Recuperado el, 24.

Orozco, Guillermo (1990), “La mediación en juego: Televisión, cultura y audiencia”, en Comunicación y Sociedad, núms.10-11.

Puiggros, A., Torres, C. A., Rodríguez Gómez, R., Gadotti, M., Russo, H., Swope, J., \& Zalmora García, B. (2017). Paulo Freire y la agenda de la educación latinoamericana en el siglo XXI.

Rodríguez, C., \& Quijano, M. (2014). Por una comunicación pensada desde las necesidades de las comunidades. MEDIACIONES, 10(12), 76-87.

Rubio, M. J., \& Escofet, A. (2013). Estudio sobre los usos de las TIC y las posibilidades de empoderamiento en las mujeres. Revista Iberoamericana de Educación, 62(3), 1-13.

Sanahuja, J. A. (2016). La agenda 2030 de desarrollo sostenible: De la cooperación Norte-Sur al imperativo universalista del desarrollo global. Gaceta Sindical, (26).

Sánchez Ruiz, Enrique (1992). Medios de difusión y sociedad: Notas críticas y metodológicas, CEIC-Universidad de Guadalajara, México.

Tassara, C., y Cecchini, S. (2016). Agenda 2030 de desarrollo sostenible: Retos de igualdad para América Latina y el Caribe. Pensamiento Propio, (44). 